\title{
Structural features of nucleoli in blood, leukemic, lymphoma and myeloma cells
}

\author{
K. Smetana
}

Clinical Section, Institute of Hematology and Blood Transfusion, U nemocnice 1, 12820 Prague 2, Czech Republic, and Department of Pharmacology, Baylor College of Medicine, 1 Baylor Plaza, 77030 Houston, USA

Accepted: 21/1/2002

Key words: nucleoli, blood, leukemia, lymphoma, myeloma cells

\section{SUMMARY}

At present, it seems clear that the nucleolus is multifunctional and represents one of the key cell organelles that participate directly or indirectly in cell resting, proliferation, differentiation and maturation states, and possibly also in programmed cell death. Thus, the morphology and cytochemistry of nucleoli may represent a very useful tool not only for the evaluation of nucleolar biosynthetic activities but also for the evaluation of various cell states under physiological, experimental and pathological conditions.

\section{INTRODUCTORY REMARKS}

Nucleoli in "normal" as well as in pathological blood cells have been a subject of a great interest to cytologists, hematologists and pathologists for a long time before nucleolar function was, at least partially, clarified. For cytologists, blood cells represented a very convenient model for studies of the nucleolus in the course of cell differentiation, maturation and aging. For hematologists and pathologists, nucleoli were a very useful tool to evaluate the abnormality of blood cells which might contribute to the elucidation of the pathogenesis of blood disorders, including malignant ones. In oncology, the morphology of nucleoli, such as size, shape and staining properties, have been used for the cytological diagnosis of malignancy since the $19^{\text {th }}$ century (see e.g. Koller, 1963; Busch and Smetana, 1970). However, it was frequently neglected that the number and size of nucleoli also depended on the cell cycle and on a variety of other factors (see Wachtler and Stahl, 1993). Nevertheless, it has been recently established that the nucleolar size represents a unique parameter for the histological assessment of the rapidity of cell proliferation in tumor lesions (Derenzini et al., 2000).

\section{Methodical notes}

Nucleoli may be visualized by a broad spectrum of cytochemical and immunocytochemical methods that facilitate the demonstration of certain nucleolar components (Fig. 1-7). However, the possibility to see very small nucleoli (the so-called micronucleoli) using "classical procedures" was limited. Therefore, numerous past studies reported the disappearance of nucleoli in terminal stages of the differentiation and maturation of blood cells including the abnormal ones (see Busch and Smetana, 1970). The visualization of micronucleoli, frequently masked by surrounding chromatin, has been facilitated by the use of light microscopic cytochemical methods for the demonstration of RNA and certain characteristic nucleolar proteins

E-mail: karel.smetana@uhkt.cz 
hand, all nucleolar types may be easily seen by conventional transmission electron microscopy (Fig. 8-11, ref. Smetana, 1980). However, the disadvantage of this approach is represented by the limited number of cell sections containing the nucleolus accessible for electron microscopy.

In discussing methods for nucleolar visualization, it should be mentioned that the previously used determination of the nucleolar number by various methods for cell identification, particularly of blastic cells, is no longer justified. The number, size and structure also depend on the state of the nucleolar activities related to the cell proliferation, resting, differentiation and maturation state (see Busch and Smetana, 1970; Smetana, 1980; Wachtler and Stahl, 1993). In addition, the nucleolar patterns reflect the cell's aging and may be influenced by the therapy of the patients or experimental conditions, in vivo as well as in vitro (Smetana and Busch, 1970; Ochs, 1998; Comai, 1999, Olson et al., 2000).

\section{The nucleolar structure and function}

At present, it seems to be clear that the nucleolus is the site of rRNA transcription, processing and assembly of preribosomal particles (Busch and Smetana, 1970; Wachtler and Stahl, 1993; Hozák et al., 1994; Stanĕk et al., 2000). Despite numerous contradictory discussions, rRNA is apparently transcribed and processed in small foci in the nucleolar regions with dense fibrillar RNA-containing components (Fig. 8) at fibrillar centers (Fig. 8, 9, 11) which represent a storage compartment of molecules necessary for the transcription and processing process. The assembly of preribosomal particles is localized in nucleolar regions
8, 11). Some studies (see Pederson, 1998; Huang et al., 1998) indicated that nucleoli are involved in the transcription and/or processing as well as the transport of other RNA species including some tRNAs and mRNAs. The detection of the small telomerase RNA within the nucleolus indicates nucleolar involvement in the function of this enzyme which synthetizes the telomeric DNA repeats at the chromosomal ends. The presence of a coiled body within the nucleolus and the presence of some nucleolar proteins in the former may reflect a possible functional link between these structures (Busch, 1997; Ochs, 1998).

\section{Main nucleolar types}

Nucleoli may be classified according to the size and distribution of RNA (see Smetana, 1980; Schwarzacher and Wachtler, 1983). Three main nucleolar types may be distinguished, such as: (a), large nucleoli with a relatively uniform distribution of RNA in the light microscope (Fig. 1-3), multiple fibrillar centers (Fig. 3, 4, 7a) and more or less distinct nucleolonemas which are easily visible in the electron microscope (Fig. 10, 11); (b), ring-shaped nucleoli with RNA only in the nucleolar peripheral part surrounding one large fibrillar center (Fig. 1, 810) and (c), micronucleoli, the size of which does not permit to see clearly the distribution of RNAcontaining structures in the light microscope (Fig. 1, 3). Micronucleoli are also easily visible in cells stained with the silver reaction for AgNORs (Fig. 6). Previous experimental studies demonstrated that large nucleoli with a relatively uniform distribution of RNA are transcribing RNA. Ring-shaped nucleoli with reduced RNA transcription are in a reversible resting state and micronucleoli are inac-

Figs. 1/7 - (1)Lymphoblast (Lybl) representing a proliferating cell with a large compact nucleolus; mature lymphocyte (Mat. Ly), containing two resting ring-shaped nucleoli and terminal lymphocyte (Term.Ly) with one inactive micronucleolus and a decreased RNA content in the cytoplasm. N - nucleus. Staining for RNA, x approx 2000. (2)Large nucleoli with unstained fibrillar centers (arrows) and less distinct nucleolonemas in an early stage of the granulocytic lineage. Staining for RNA, $\mathrm{x}$ approx. 2800. (3)Large and irregularly shaped nucleolus (arrow) in a proerythroblast (Proery) which is replaced by several small nucleoli (small arrows) in a further developmental stage - basophilic erythroblast (Basoebl). N - nucleus. Staining for RNA, x approx. 2200. (4)The different distribution of AgNORs in a large nucleolus (large arrow) and small nucleoli (small arrows), the better visualization of which was facilitated by the image processing. $\mathrm{N}$ - nucleus. Silver reaction, $\mathrm{x}$ approx. 3300. (5)Satellite nucleoli (arrows) stained with the silver reaction for AgNORs in an early stage of the leukemic granulocytic lineage. X approx. 3600 using the image processing. (6)Advanced stages of the granulocytic (on the left) and erythroid differentiation containing micronucleoli (arrows) stained with the silver reaction for AgNORs. C - cytoplasm. X approx. 2100. (7)PHA stimulated lymphocytes (Ly) entering to S phase immunostained for nucleolin (C23 protein) and nucleophosmin (B23 protein) a. Nucleolin is positive in 3 fibrillar centers and adjacent nucleolar regions (arrow). b. Nucleophosmin is rather uniformly distributed (arrow). $\mathrm{Ne}-$ neutrophil. Low contrast printing to facilitate cell visualization. X approx. 2500. 
It should be added that some cells may contain various types of nucleoli within the same nucleus. In such case, the more active nucleolus is the dominant one (Smetana et al., 1996).

Large active nucleoli characteristic of early stages of all blood cell lineages, are replaced by less active ring-shaped nucleoli and/or inactive micronucleoli during further differentiation and maturation (see Smetana, 1980). In the erythroid lineage, the transformation of active, irregularly shaped nucleoli occurs already in the stage of basophilic erythroblasts; in the granulocytic lineage, in myelocytes, and in the monocytic lineage, in promonocytes. In the lymphocytic and plasmacytic lineages, mature cells are characterized by the presence of ringshaped nucleoli in a reversible resting state which transforms to micronucleoli in terminal stage; or in lymphocytes, to active large nucleoli after blastic stimulation (Smetana, 1980).

The number of lymphocytes in the peripheral blood, classified according to the presence of main nucleolar types, may be a useful marker of their activity in a variety of diseases including malignant ones (see Smetana, 1980). The premature loss of nucleoli and ribosomal cistrons has been regularly noted in erythroblasts of refractory anemias of the myelodysplastic syndrome (Mamaev et al., 1997; Smetana et al., 1999a). Such abnormality reflects an alteration in the renewal of preribosomal particles and participates in the premature programmed cell death of these cells, and thus contributes to the pathogenesis of this disease.

Nucleolar asynchrony is expressed by the presence of an active large nucleolus and a resting ringshaped nucleolus in one and the same nucleus in one and the same cell (Fig. 10). Such cells seem to be more resistant to cytotoxic or cytostatic treatment (Smetana et al., 1997). The nucleolar asynchrony is mainly observed in leukemic myeloblasts, and less frequently, in lymphoblasts (Smetana et al., 1999c) or in immature leukemic monocytes as well as in myeloma plasmacytes. lar types within the same nucleus (Fig. 5) are called satellite nucleoli. They represent single nucleolar organizers which do not fuse or participate in the formation of a characteristic nucleolus. In situ hybridization has demonstrated the presence of rDNA confirming that these are real nucleoli (Smetana et al., 1993). It should be added that the number of cells with satellite nucleoli decreases after mitogenic stimulation accompanied by increased RNA transcription, and increases when the transcription of this nucleic acid is inhibited.

\section{Nucleolar silver stained particles-AgNORs in interphasic cells}

At present, AgNORs (Fig. 4-6) are widely used for the evaluation of nucleolar transcriptional activities and cell proliferation potential (Busch et al., 1979; Trere et al., 1989; Derenzini, 2000). Their number or size usually correlates with other proliferation markers (Thiele and Fischer, 1993). In this regard, it should be mentioned that the reported differences in the number of AgNORs in various cells depend not only on cell differentiation, maturation, proliferation, resting and aging states but also on methods for their visualization. The silver reaction may exhibit positivity of various nucleolar compartments and the whole nucleolar body depending on proteins reacting with silver under various conditions (Smetana et al. $1999 b)$. The most useful information is provided by the silver reaction of proteins, such as RNA polymerase I, UBF and nucleolin, in fibrillar centers and adjacent nucleolar areas containing fibrillar components. In such case, the positivity of the silver reaction apparently corresponds to interphasic AgNORs. The number of silver-stained particles-AgNORs is highest in immature proliferating blood cells and gradually decreases in the course of their maturation and differentiation (Smetana et al., 1984; Grotto et al., 1991; Janoutová and Likovský, 1995). Large nucleoli contain clusters

Figs. 8/11 - (8)Electron micrograph of a ring-shaped nucleolus in a lymphocyte showing a fibrillar center (FC), dense fibrillar RNA-containing components (DFC), granular RNP components (GC) and perinucleolar chromatin (Ch). X approx. 68000. (9)A ring-shaped nucleolus (pointers) in a leukemic lymphocyte stained for AgNORs. The silver stained proteins are in protrusionlike regions (arrows) at a large fibrillar center (FC). The nucleolar periphery - Pe. X approx. 55000. (10)Nucleolar asynchrony in a myeloma plasmablast. Compact nucleolus without distinct nucleolonemas (Co), characteristic ring-shaped nucleolus (RS) with RNA-containing structures surrounding a large fibrillar center . X approx. 32000. (11)A large nucleolus with distinct nucleolonemas (pointer). Nucleolar regions containing dense fibrillar components (DF) and granular components (G). Fibrillar center (white arrow), perinucleolar chromatin (Ch) and a perichromatin granule (black arrow). x approx. 64000. 
micronucleoli, including satellite nucleoli, the number of AgNORs is substantially reduced-usually to 1 AgNOR (Fig. 4-6). The number of AgNORs may be different in nucleoli within the same nucleus (Fig. 4). Such asymmetric distribution apparently indicates differences in nucleolar biosynthetic activity, and larger nucleoli with a larger number of AgNORs might be functionally dominant (Smetana et al. 1999d).

Nucleolar development in granulocytic precursors in the chronic phase of chronic myeloid leukemia is similar to that in the "normal" nonleukemic granulocytic lineage, except for a lower number of clustered AgNORs (Gilberti et al., 1995). Myeloblasts in acute myeloid leukemias are characterized by a reduction in the nucleolar number as well as the number of AgNORs, which might be used as a prognostic marker (Trnĕný and Smetana, 1993; Grotto et al., 1995; Pich et al., 1998). This abnormality may be related to the prolonged cell cycle of these cells and/or their decreased proliferation potential. It should be also added that some leukemic myeloblasts or lymphoblasts contain only micronucleoli, as do fully mature and not-proliferating cells. Such cells might correspond to aging non-proliferating leukemic blasts which were reported in earlier studies (see Smetana et al., 1996).

As in other malignant diseases, in malignant lymphoproliferative disorders and multiple myeloma, the increased number of AgNORs is usually associated with a more aggressive and rapid course of the disease (Crocker 1992; Pich et al., 1992; Mikou, 1993; Kalir et al., 1994, Mamaev et al., 1997). At this point, it should be mentioned that a high percentage of leukemic lymphocytes in chronic lymphocytic leukemia possess ring-shaped nucleoli with the re-distributed silver stained proteins at fibrillar centers, similar to stimulated lymphocytes at the end of the early G1 phase. Thus, these leukemic lymphocytes are apparently not in the presumed G0 phase and might be sensitive to the current cytostatics acting on the G1 phase (Smetana et al., 1995).

\section{Selected nucleolar proteins as markers of the nucleolar and cell proliferation activities}

Only some nucleolar proteins, among the several which may be visualized by immunocytochemistry, are widely used as markers of the cell prolif- that the localization of them depends on a great variety of factors including their intranuclear transport and translocation. PCNA (Proliferating Cell Nuclear Antigen), commonly used as a marker of cell proliferation activity, is expressed in the nucleolus starting with the late G1 phase and is especially accumulated in the $\mathrm{S}$ phase (Smetana et al., 1983; Kurki et al., 1986). RNA polymerase I is present in fibrillar centers and adjacent nucleolar regions, the number of which is enlarged when the cell increases the transcription of rRNA and proliferates. Thus, this enzyme is also a useful marker for these nucleolar compartments even at the light microscopic level (Ochs and Smetana, 1989). Nucleophosmin (Fig. 7b), mainly present in nucleolar regions containing granular components representing preribosomes, is a promising marker of the cell sensitivity to cytostatic drugs. The translocation of this protein from nucleoli was noted under experimental conditions in leukemic cells sensitive to the cytostatic treatment (Chan et al., 1999; Busch, 1977). Other nucleolar proteins might be also important as markers of nucleolar and cell proliferation activity in the future, but at present, they rather serve as markers for the light microscopic localization of nucleolar functional components (Fig. 7a).

\section{Nucleoli in programmed cell death-apoptosis}

There is only limited information on nucleoli in the course of the cell terminal maturation and apoptosis. However, cell terminal maturation is usually accompanied by the transformation of nucleoli to micronucleoli, and in some cells, such as pathological erythroblasts or maturing granulocytes, by their disappearance. From a cytochemical point of view, it seems likely that micronucleoli lose their RNA, and the nucleolar remnants bodies consist mainly of characteristic nucleolar proteins (Smetana et al., 2001). In the electron microscope, these remnants are represented by residual fibrillar centers or protein filamentous bodies (Zatsepina et al., 1988; Ochs and Smetana, 1989), in some of which the nucleolar components may be segregated (Smetana, 1980). Recently, it has been shown that residual nucleolar components in apoptotic blood cells, or other cell types, may be a part of heterogeneous aggregates called 'heterogeneous ectopic RNPderived structures' (HERDS) in the nucleus; and 
nucleolus-like bodies (Biggiogera et al., 1997; Pellicciari et al., 2000).

Recent experiments have demonstrated that apoptosis induced directly, without preceding terminal differentiation in leukemic granulocytic precursors, is not accompanied by the nucleolar transformation to micronucleoli. In these apoptotic cells, nucleoli are characterized by a marked reduction of AgNORs, which is also related to the alteration of nucleolar transcription and cell proliferation (Smetana et al., 2000).

\section{ACKNOWLEDGEMENTS}

This minireview was facilitated in part by the support of the Grant Agency of the Czech Ministry of Health, VZ 237360001 and Busch Fund.

\section{REFERENCES}

Biggiogera M., Bottone M.G., and Pelliciari C.: Nuclear ribonucleoprotein-containing structures undergo severe rearrangement during spontaneous thymocyte apoptosis. Histochem. Cell Biol. 107, 331-336, 1997.

Busch H.: Nucleolar and nucleolonemal proteins of cancer cells. J. Tumor Marker Oncol. 12, 5-68, 1997.

Busch H., and Smetana K.: The nucleolus. Academic Press, New York, 1970.

Busch H., Daskal Y., Gyorkey, F., and Smetana K.: Silver staining of nucleolar granules in tumor cells. Cancer Res. 39, 857-863, 1979.

Chan P.K., Chan F.Y.: A study of correlation between NPMtranslocation and apoptosis in cells induced by Daunomycin. Biochem. Pharmacol. 57, 1265-1273, 1999.

Comai I.: The nucleolus: a paradigm for cell proliferation and aging. Braz. J. Med. Biol. Res. 32, 12, 1473-1478, 1999.

Crocker J.: Histochemistry of malignant lymphomas: review of conventional histochemical, enzyme histochemical, and argyrophil nucleolar organizer region stains. J. Histotechnol. 15, 185-197, 1992.

Derenzini M.: The AgNORs. Micron. 31, 11, 117-120. 2000.

Derenzini, M., Trere D., Pession A., Govoni M., Sirri V., and Chieco P.: Nucleolar size indicates the rapidity of cell proliferation in cancer tissues. J. Pathol. 191, 181-186, 2000.

Gilberti M.F., Metze K., and Lorand-Metze I.: Changes of nucleolar organizer regions in granulopoietic precursors during the course of chronic myeloid leukemia. Ann. Hematol. 71, 275-279 1995.

organizer regions in normal hematopoiesis: relationship to cellular proliferation and maturation. Nouv. Rev. Fr. Hematol. $33,1-4,1991$.

Grotto H.Z.W., Metze K., and Lorand-Metze I.: Pattern of nucleolar organizer regions in human leukemic cells. Analyt. Cell. Pathol. 5, 203-212, 1993.

Hozák P., Cook P.R., Schofer Ch., Mosgoller W., and Wachtler F.: Site of transcription of ribosomal RNA and intranucleolar structure in Hela cells. J. Cell Sci. 107, 639-648, 1994

Huang S., Deerinck TJ., Ellisman M.H., and Spector D.L.: The perinucleolar compartment and transcription. J. Cell Biol. 143, 35-47, 1998

Janoutová J., Likovský Z.: Nucleoli and argyrophil nucleolus organizer regions (AgNORs) of cells of the megacaryocytic line in the rat. Physiol. Res. 44, 193-196, 1995.

Kalir T., Chan K.S., Liu Z., Strauchen J., and Gill J.: Semiautomatic quantitation of nucleolar organizer regions in nonHodgkin lymphomas. Path. Res. Pract. 190, 124-128, 1994.

Koller P.C.: The nucleus of cancer cells. Exp. Cell Res. Suppl. 9, 3-14, 1963.

Kurki P., Vanderlaan M., Dolbeare F., Gray J., and Tan E.M.: Expression of proliferating cell nuclear antigen (PCNA)/cyclin during the cell cycle. Exp. Cell Res. 166, 209-219, 1986.

Mamaev N.N., Medvedeva N.V., Shist V.F., Markochev A. B., and Pasternak N.D.: Nucleoli and AgNORs in Hodgkin's disease. J. Clin. Molec. Pathol. 50, 149-152, 1997.

Mamaev N.N., Salogubov G.N., and Nefedova I.B.: Interphase ribosomal RNA cistron silver staining in refractory anemia with and without excess blasts. J. Clin. Mol. Pathol. 50, 92-95, 1997.

Mikou P., Kanavaros P., Aninos D., Tzardi M., Karameris A., Gorgoulis B., Papadoupoulos N., Lavergne A., and Galian A.: Nucleolus organizer regions (NORs) staining and proliferating cell nuclear antigen (PCNA) immunostaining in mucosaassociated lymphoid tissue (MALT) gastric lymphomas. Path. Res. Pract. 189, 1004-1009, 1993.

Ochs R.L.: Methods used to study structure and function of the nucleolus. Methods in Cell Biology 53, 303-321, 1998.

Ochs R.L., and Smetana K.: Fibrillar center distribution in nucleoli of PHA-stimulated human lymphocytes. Exp. Cell Res. 184, 552-557, 1989.

Ochs R.L., and Smetana K.: Detection of fibrillarin in nucleolar remnants and the nucleolar matrix. Exp. Cell Res. 197, 183190, 1991.

Olson M.O., Dundr M., and Szebeni A.: The nucleolus: an old factory with unexpected capabilities. Trends Cell Biol. 10, 189-196, 2000.

Pederson T.: The plurifunctional nucleolus. Nucleic Acids Re. 26, 3871-3876, 1998.

Pellicciari C., Bottone M.G., Scovassi A.I., Martin T.E., Biggiogera M.: Rearrangement of nuclear ribonucleoproteins and 
hypertonic stress. Eur. J. Histochem. 44, 247-254, 2000.

Pich A., Chiusa L., Audisio E., and Marmon F.: Nucleolar organizer region counts predicts complete remission, remission duration, and survival in acute myelogenous leukemia patients. J. Clin. Oncol. 16, 1512-1518, 1998.

Pich A., Marmont F., Chiusa L., Capello N., Resegotti L., and Navone R.: Argyrophilic nucleolar organizer region counts and prognosis in multiple myeloma. Brit. J. Haematol. 82, 681-688. 1992.

Schwarzacher H.G., and Wachtler F.: Nucleolus organizer regions in nucleoli. Hum. Genet. 63, 89-99, 1983.

Smetana K.: Nucleoli in maturing blood cells. In: Topical Reviews in Haematology, vol. 1 (Ed. S. Roath) Wright, Bristol, pp. 115-137, 1980.

Smetana K., Cajthamlová H., Greben̆ová D., and Hrkal Z.: The 5-aminoloaevulinic acid-based photodynamic effects on nucleoli and nucleoli of HL-60 leukemic granulocytic precursors. J.Photochem. Photobiol. B: Biol. 59, 80-86, 2000.

Smetana K., Gyorkey F., Chan P.K., Tan E., and Busch H.: Proliferating cell nucleolar antigen (PCNA) and human malignant tumor nucleolar antigen (HMTNA) in nucleoli of human hematological malignancies. Blut 46, 133-141, 1983.

Smetana K., Jirásková I., Čermák J.: Incidence of nucleoli in patients suffering from refractory anemia of myelodysplastic syndrome. Eur. J. Haematol. 63, 332-336, 1999a

Smetana K., Jirásková I., Perlaky L., and Busch H.: The silver reaction of nucleolar proteins in the main structural compartments of ring-shaped nucleoli in smear preparations. Acta Histochem. 101, 167-183, 1999b.

Smetana K., Jirásková I., and Sedláčková M.: Distribution of silver stained proteins (SSPs) in ring shaped nucleoli of leukemic lymphocytes. Acta histochem. 97, 175-181, 1995.

Smetana K., Jirásková I., Smetana K. jr., Čermák J.: A short note on micronucleoli in the course of terminal maturation of human erythroblasts. Folia Biol. (Praha) 47, 14-17, 2001

Smetana K., Jirásková I., and Starý J.: The number of nucleoli and main nucleolar types in lymphoblasts of children suffering from acute lymphoid leukemia. Hematology 4, 231-236,1999c.

Smetana K., and Likovský Z.: Nucleolar silver-stained granules in maturing erythroid and granulocytic cells. Cell Tissue Res. 237, 236-370, 1984.

Smetana K., Likovský Z., Jirásková I., C̆ermák J.: The asymmetric distribution of interphasic silver-stained nucleolus organizer regions in human and rat proerythroblasts. Folia Biol. (Praha) 45, 243-246, 1999d.

Smetana K., Rosa L., Jirásková I., Chan P.K., Lesáková D., and Šubrtová H.: Nucleolar asynchrony in blastic cells of acute myeloid leukemia - possible connection with the drug resistance? In: Therapie der leukämien und lymphomen, Beitr. Oncol. (Eds. Fleischer J., Hiddeman W., Hoelzer W.) Karger, Basel, pp. 36-41, 1997. er H.G., Jirásková I., Ochs R.: cytochemistry of satellite nucleoli in human lymphocytes. Acta histochem. 95, 228-231, 1993.

Smetana K., S̆ubrtová H., Jirásková I., Klamová H., Lemež P., and Rosa L.: Nucleoli in circulating blasts of acute myeloid and lymphoid leukemia - on the incidence of ring shaped nucleoli and micronucleoli. Hematology Reviews 9, 291-300, 1996.

Stanĕk D., Kiss T., and Raška I.: Pre-ribosomal RNA is processed in permeabilized cells at the site of transcription. Eur. J. Cell Biol. 79, 202-207, 2000.

Thiele J., and Fischer R.: Bone marrow tissue and proliferation markers: results and general problems. Virchows Arch. A Pathol. Anat. 423, 409-416, 1993.

Trerè D., Pession A., and Derenzini M.: The silver-stained proteins of interphasic nucleolar organizer regions as a parameter of cell duplication rate. Exp. Cell Res. 184, 131-137, 1989.

Trnĕný M., and Smetana K.: Nucleolus organizer regions in acute leukemia. In: Leukemias (Ed. Fleischer J.) Springer, Berlin, pp. 15-17, 1993.

Wachtler F., and Stahl A.: The nucleolus: A structural and functional interpretation. Micron 24, 473-505, 1993.

Zatsepina O.V., Chelidze P.V., and Chentsov Y.S.: Changes in the number and volume of fibrillar centers with the inactivation of nucleoli at erythropoiesis. J. Cell Sci. 9, 439-448, 1989. 